\title{
A MUSCLE-TENDON TRANSPOSITION FOR PARALYSIS OF THE LATERAL ABDOMINAL MUSCLES IN POLIOMYELITIS
}

\author{
John M. P. Clark, Leeds, England \\ Orthopaedic Surgeon, General Infirmary, Leeds \\ and \\ Anatol Axer, Tel-Aviv, IsRael \\ Orthopaedic Surgeon, Assaf Harofe Hospital, Zrifin
}

An attempt to compensate for some of the deficiency of paralysed abdominal muscles was first made by Lowman (1932) when he introduced the method of using a fascial transplant. Mayer (1944) broadened the concept of paralytic deformities from imbalance of the trunk muscles by his description of fixed paralytic pelvic obliquity. This condition may be caused either by abnormalities of the pelvi-femoral muscles such as unilateral contracture of the abductor muscles of the hip, or by unilateral weakness or paralysis of the abdominal muscles and the quadratus lumborum. To improve the strength of the paralysed trunk muscles, Mayer advised that the fascial transplant recommended by Lowman be modified by running it from bone to bone, usually from the iliac crest to the ninth rib. This operation, though not a complete replacement of the paralysed muscles, had a beneficial result as reported in a number of communications (Mayer 1931, 1936). The fascial graft hypertrophied and became strong enough to prevent a recurrence of the pelvic obliquity.

In studying a large group of children paralysed during the severe epidemics of poliomyelitis of 1950 and 1951 in Israel the authors conceived the idea of using the tensor fasciae latae and the ilio-tibial band as an active muscle-tendon transplant. This procedure seemed to have an advantage over the free fascial graft of Lowman and Mayer by the employment of the active muscular power of the tensor fasciae latae. Later it was learnt that a similar transplant had been designed by Hey Groves and practised by Forrester-Brown (1950), but no account of the operation was published. The object of this communication is to record the method, which was independently developed by the authors, to discuss the indications for the operation, and to give some assessment of the results.

\section{OPERATIVE TECHNIQUE}

The first stage of the operation is concerned with the exposure and freeing of the tendinous part of the muscle-tendon transplant which consists of the ilio-tibial band. The band is

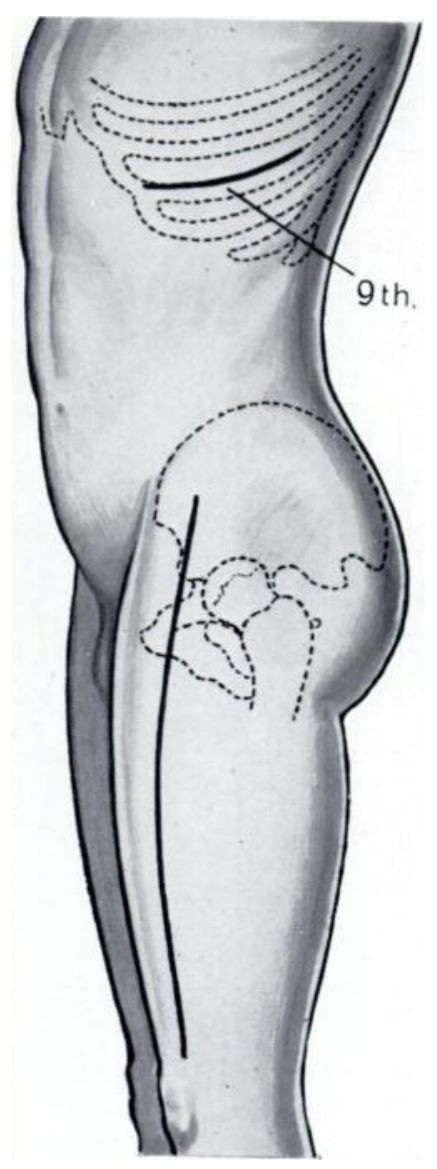

FIG. 1 exposed through a longitudinal incision extending down the lateral aspect of the thigh from half way between the iliac crest and the greater trochanter of the femur to the outer aspect of the knee (Fig. 1). Cleared of the superficial fascia the ilio-tibial band is readily visible, 
and is divided transversely as low as possible on the lateral femoral condyle to produce a strip five centimetres wide to be dissected proximally. At the first lifting of the lower end of the transplant it is necessary to cut its deep attachment to the lateral intermuscular septum (between the vastus lateralis and the biceps femoris) which binds the band to the femur. The dissection of the strip proceeds upwards, and after reaching the tensor fasciae latae muscle the dissection is then carried over and above the greater trochanter. At this point in the operation the lower two-thirds of the incision is sutured. Even in small children the operation is easy to perform and there is no need for blood transfusion if care be exercised

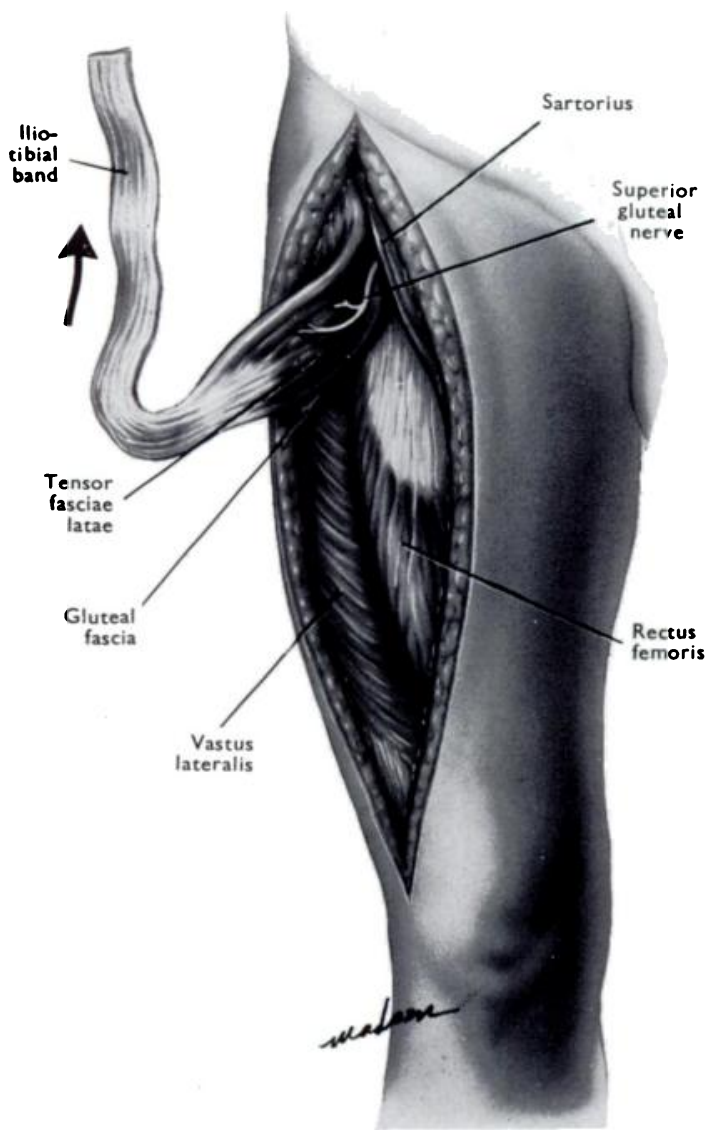

Fig. 2

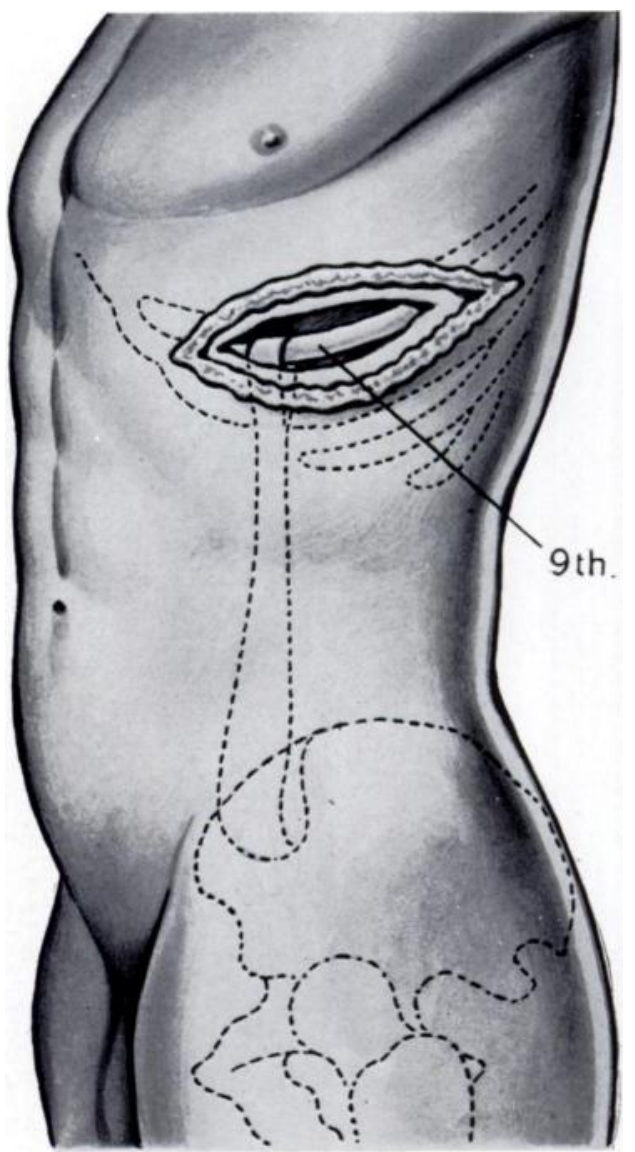

Fig. 3

Figure 2-Isolation and mobilisation of musculo-tendinous transplant. Figure 3-Transposition of musculo-tendinous transplant.

to cover up the raw areas as soon as possible. In some of the earlier operations there was failure to obtain a dynamic transplant although pre-operative clinical examination had revealed an active tensor fasciae latae. We now always stimulate the muscular part of the transplant with a faradic current by means of a bipolar electrode before proceeding to the second stage of the operation. If the tensor fasciae latae muscle is macroscopically normal faradic stimulation will produce a vigorous contraction. The free end of the ilio-tibial band, supported away from the skin on forceps in about its normal anatomical position, will move proximally about three centimetres when its motor contracts. With the free end of the ilio-tibial band placed over the skin of the lower ribs (which is approximately the site of its future attachment) faradic stimulation of the muscle does not move the end of the ilio-tibial band until the muscle 
belly has been isolated from the neighbouring muscles. The tensor fasciae latae must be dissected from the lateral intermuscular septum, away from the gluteal muscles and fasciae and must be separated from the origin of sartorius. The nerve supply of the tensor muscle (the terminal fibres of the superior gluteal nerve) and as much as possible of the blood supply of the muscle must be preserved (Fig. 2). When the proper isolation of the contractile part of the transplant has been achieved it will be found that the excursion of the free end of the ilio-tibial band will be about one-third of that previously noted when the muscle and band were in their normal anatomical positions.

The second stage of the operation is concerned with the exposure of the new site of insertion and with the preparation of the subcutaneous tunnel through which the transplant

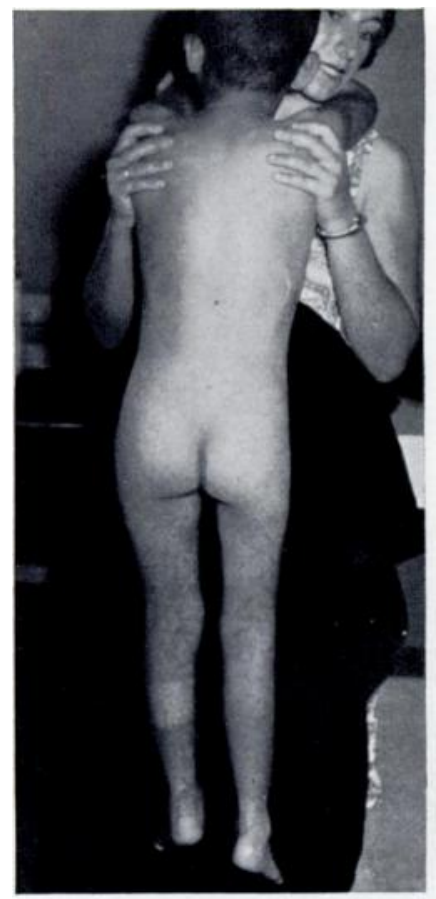

Fig. 4

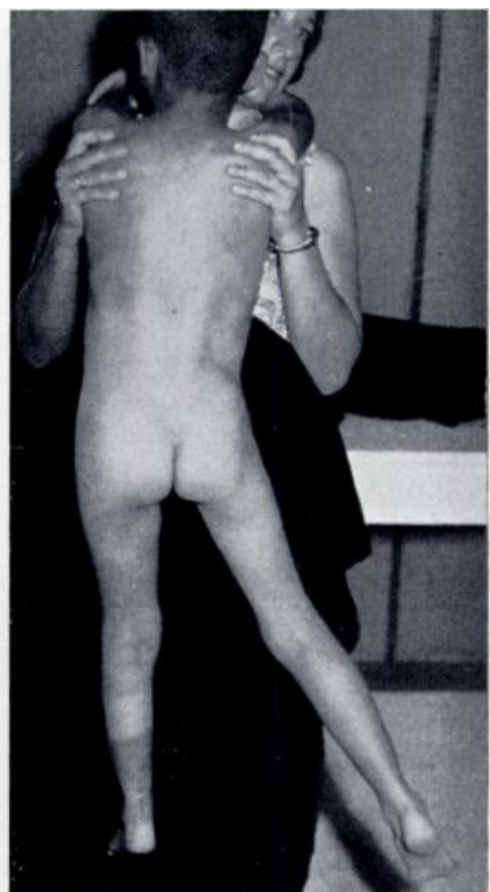

Fig. 5

Figure 4-After operation. Slight right pelvic drop still present when child is suspended and relaxed. Figure 5-Same child in suspension. Right pelvic drop is over-corrected during active abduction of the thigh which causes contraction of the active transplant with its tendon (the ilio-tibial band seen bulging under the skin) attached to the ninth rib to lift the right side of the pelvis.

will run. An incision eight centimetres long is made in the long axis of the ninth rib forwards and downwards from the axillary line (Fig. 1) to expose the underlying rib. After excision of the periosteum of the rib in the same line as the skin incision the bone is stripped on all its surfaces for a distance of six centimetres. A subcutaneous tunnel is now needed between the upper end of the thigh incision and the costal incision. This tunnel can be made quite easily by thrusting a pair of sponge forceps up from below and opening them out until the required area of alveolar tissue is cleared. The tunnel must be wider at the lower end than at the upper to accommodate the greater bulk of the upturned muscle belly of the tensor fasciae latae (Fig. 3). It may be necessary in the second stage of the operation to sever contracted bands about the hip because of the frequency of abduction-flexion contractures in this region in poliomyelitis. 
The third stage of the operation consists in threading the transplant through the tunnel and wrapping the free end of the ilio-tibial band round the prepared rib from below, within and over outwards to be sutured upon itself and to the replaced periosteum. The transplant ought to be sutured at moderate tension, with the iliac crest brought sufficiently nearer to the ribs to produce a slight lateral curve of the lumbar spine concave to the same side. Any scoliosis must be corrected as much as possible before the operation, because the transplant is not actively corrective and will only be powerful enough to maintain correction. Electrical stimulation of the tensor fasciae latae at this stage will produce slight tension of the transposed ilio-tibial band under the skin which is palpable and similar to the voluntary action of the muscle that will be demonstrable in a successful result. After closure of the wounds a plaster spica is applied to include both limbs and the trunk from the nipples down; the leg on the side of operation is best fixed in adduction, extension and medial rotation at the hip if an abduction-flexion contracture has had to be corrected. The plaster spica is kept in position for six weeks, and after its removal non-weight-bearing exercises are begun. The first active exercises are directed towards starting activity in the tensor fasciae latae by training the patient in the original action of this muscle-namely abduction with flexion and medial rotation of the hip. After a time the dynamic nature of the transplant ought to be demonstrable by palpable tension occurring in the ilio-tibial band when its motor contracts in conjunction with the active movement of the thigh.

Figure 4 shows a boy suspended after operation on the right side. There is a slight right pelvic drop when the boy hangs relaxed. Figure 5 shows the same boy over-correcting the pelvic drop by active abduction, with flexion and slight medial rotation of the right lower extremity. This movement causes contraction of the active transplant which, by means of its tendon (the ilio-tibial band seen bulging under the skin) attached to the ninth rib lifts actively the right side of the pelvis.

The activities of the transplant must be synchronised with active raising of the pelvis if this action has not been entirely lost or, in the presence of absolute paralysis of the lateral abdominal muscles, an increasing load is placed on the active transplant by applying traction to the leg on the affected side. After six to eight weeks of non-weight-bearing exercises walking with the aid of crutches or elbow-crutches may be started.

\section{DISCUSSION}

A chronological analysis of this series of patients is given in Table I. In seventeen out of the twenty-four patients paralysis occurred within the first two years of life; nine infants contracted poliomyelitis within the first year and eight within the second year of life. The interval between the onset of the disease and the operation will necessarily depend often on when the patient first comes under observation. In times of epidemic this interval is likely to be short because under the modern concept of treating the disease the orthopaedic surgeon forms one of the team responsible for the management of the patient from the beginning. In this series of twenty-four patients the longest interval between the onset of the disease and the operation was seven years (because these patients came late under observation) and the shortest was eight months. One patient was operated on within the first year of the disease, twelve within the second year and eight within the third year. The youngest age at the time of operation was twenty-two months. An analysis of the reasons used for the selection of the patients in this series is given in Table II, and it is correlated with the clinical estimation of the results at the latest time of the follow-up that has been possible in view of the recent date of the later operations. The longest follow-up is three years and nine months, the shortest is one year and one month, the average being 23.3 months.

Nineteen patients showed a lateral pelvic tilt before operation, with asymmetrical weakness of the lateral abdominal muscles; fourteen were corrected by the operation, four were improved and one remained unchanged. Bilateral operation for forward pelvic tilt was performed in 
only one patient, but the tilt did not alter after the operation although the antero-lateral abdominal muscles gained strength from the "internal splintage" of the abdominal wall. Disparity in leg length was noted in thirteen patients; in seven it was corrected by the operation, in five it was improved, and in the remaining patient there was no change.

TABLE I

Twenty-four Cases of Muscle-Tendon Transposition for Paralysis of the lateral Abdominal Muscles in Poliomyelitis

\begin{tabular}{|c|c|c|c|c|c|c|c|c|c|}
\hline \multirow[t]{2}{*}{$\begin{array}{c}\text { Case } \\
\text { affected }\end{array}$} & \multirow[t]{2}{*}{$\begin{array}{c}\text { Side } \\
\text { affected }\end{array}$} & \multirow[t]{2}{*}{$\begin{array}{c}\text { Onset of } \\
\text { poliomyelitis }\end{array}$} & \multicolumn{2}{|c|}{ Age at onset } & \multirow[t]{2}{*}{$\begin{array}{c}\text { Date of } \\
\text { operation }\end{array}$} & \multicolumn{2}{|c|}{$\begin{array}{c}\text { Age at } \\
\text { operation }\end{array}$} & \multirow{2}{*}{\multicolumn{2}{|c|}{$\begin{array}{l}\text { Interval between } \\
\text { onset and operation } \\
\text { years months }\end{array}$}} \\
\hline & & & years & months & & years & months & & \\
\hline 1 & Both & June 1950 & 1 & 7 & $\begin{array}{ll}\text { Oct. } & 1951 \\
\text { Jan. } & 1952\end{array}$ & 3 & 0 & 1 & 4 \\
\hline 2 & Left & May 1950 & 5 & 0 & Nov. 1951 & 6 & 6 & 1 & 6 \\
\hline 3 & Right & June 1951 & 1 & 2 & Feb. 1952 & 1 & 10 & 0 & 8 \\
\hline 4 & Right & June 1950 & 2 & 0 & Mar. 1952 & 4 & 0 & 1 & 9 \\
\hline 5 & Right & May 1950 & 0 & 10 & May 1952 & 2 & 10 & 2 & 0 \\
\hline 6 & Right & Dec. 1951 & 3 & 9 & Jan. 1953 & 4 & 10 & 1 & 1 \\
\hline 7 & Right & Dec. 1951 & 2 & 0 & Feb. 1953 & 3 & 2 & 1 & 2 \\
\hline 8 & Right & Aug. 1951 & 1 & 3 & July 1953 & 4 & 2 & 2 & 11 \\
\hline 9 & Left & May 1952 & 0 & 9 & Aug. 1953 & 2 & 0 & 1 & 3 \\
\hline 10 & Right & June 1951 & 0 & 10 & Aug. 1953 & 3 & 0 & 2 & 2 \\
\hline 11 & Right & June 1946 & 29 & 0 & Aug. 1953 & 36 & 0 & 7 & 0 \\
\hline 12 & Left & - 1951 & 1 & 0 & Nov. 1953 & 3 & 0 & 2 & 0 \\
\hline 13 & Right & Nov. 1951 & 0 & 6 & Nov. 1953 & 2 & 6 & 2 & 0 \\
\hline 14 & Right & Dec. 1951 & 4 & 6 & Nov. 1953 & 6 & 5 & 1 & 11 \\
\hline 15 & Left & June 1951 & 1 & 8 & Dec. 1953 & 4 & 2 & 2 & 6 \\
\hline 16 & Left & June 1947 & 2 & 0 & Mar. 1954 & 9 & 0 & 7 & 0 \\
\hline 17 & Right & Jan. 1952 & 0 & 5 & Mar. 1954 & 2 & 6 & 2 & 1 \\
\hline 18 & Right & Oct. 1952 & 1 & 0 & Mar. 1954 & 2 & 4 & 1 & 4 \\
\hline 19 & Left & Nov. 1951 & 0 & 11 & May 1954 & 3 & 6 & 2 & 6 \\
\hline 20 & Right & June 1951 & 1 & 5 & May 1954 & 4 & 4 & 2 & 11 \\
\hline 21 & Right & June 1952 & 2 & 5 & June 1954 & 4 & 7 & 2 & 0 \\
\hline 22 & Right & Apr. 1952 & 0 & 6 & June 1954 & 2 & 8 & 2 & 2 \\
\hline 23 & Left & Oct. 1951 & 3 & 6 & June 1954 & 6 & 3 & 2 & 9 \\
\hline 24 & Left & Oct. 1949 & 2 & 5 & Aug. 1954 & 7 & 2 & 4 & 9 \\
\hline
\end{tabular}

Thoraco-pelvic stability and gait were materially improved in eleven patients, and in ten of these the transplant was active. In the patient whose transplant was passive three-point walking was successfully changed to four-point walking because he is able to hang the right side of the pelvis from the ipsilateral ribs when using crutches, and progression is achieved by a rotatory movement of the thorax which enables him to swing his right foot through

VOL. 38 B, NO. 2, MAY 1956 
TABLE II

INDICATIONS AND RESULTS OF OPERATION

\begin{tabular}{|c|c|c|c|c|c|}
\hline \multirow{2}{*}{ 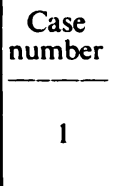 } & \multirow{2}{*}{$\begin{array}{c}\text { Side } \\
\text { affected }\end{array}$} & Indications & \multicolumn{2}{|c|}{$\begin{array}{l}\text { Follow-up } \\
\text { years months }\end{array}$} & Result \\
\hline & & $\begin{array}{l}\text { Weak lateral abdominals. } \\
\text { pelvic tilt. Increased } \\
\text { lordosis. } \\
\text { Thoraco-pelvic instability }\end{array}$ & 3 & 9 & $\begin{array}{l}\text { Abdominals much improved. Tilt } \\
\text { unchanged. Lordosis less. T.-P. } \\
\text { instability less. Both transplants active }\end{array}$ \\
\hline 2 & Left & $\begin{array}{l}\text { Weak left lateral abdominals. Left } \\
\text { pelvic tilt. Scoliosis, apex L. } 1 \text {, partly } \\
\text { fixed. Left leg longer by } 3 \frac{1}{2} \text { centi- } \\
\text { metres. Unable to walk }\end{array}$ & 3 & 8 & $\begin{array}{l}\text { Transplant weak. Pelvic tilt improved. } \\
\text { Scoliosis slightly worse. Disparity in } \\
\text { leg length reduced to } 1 \text { centimetre. Can } \\
\text { walk in braces when supported by } \\
\text { elbows }\end{array}$ \\
\hline 3 & Right & $\begin{array}{l}\text { Weak left lateral abdominals. Right } \\
\text { pelvic tilt. Scoliosis, apex L.2, partly } \\
\text { fixed }\end{array}$ & 3 & 5 & $\begin{array}{l}\text { Transplant passive. Pelvis level. } \\
\text { Scoliosis slightly worse. Walks } \\
\text { (braces and crutches) }\end{array}$ \\
\hline 4 & Right & $\begin{array}{l}\text { Weak right lateral abdominals. Right } \\
\text { pelvic tilt. Right leg longer by } 1 \frac{1}{2} \\
\text { centimetres. Thoraco-pelvic insta- } \\
\text { bility. "Screw walking" }\end{array}$ & 3 & 4 & $\begin{array}{l}\text { Transplant active. Pelvis level. } \\
\text { Disparity in leg length reduced to } \\
1 \text { centimetre. T.-P. instability much } \\
\text { less. "Screw walking" much less } \\
\text { and can run }\end{array}$ \\
\hline 5 & Right & $\begin{array}{l}\text { Weak right lateral abdominals. Right } \\
\text { pelvic tilt. Right leg longer by } 2 \frac{1}{2} \\
\text { centimetres. Cannot walk }\end{array}$ & 3 & 2 & $\begin{array}{l}\text { Transplant weak. Pelvis level. Leg } \\
\text { length equal. Walking with limp } \\
\text { owing to subluxation hip }\end{array}$ \\
\hline 6 & Right & $\begin{array}{l}\text { Weak right lateral abdominals. Right } \\
\text { pelvic tilt. Right leg longer by } 2 \text { centi- } \\
\text { metres. Thoraco-pelvic instability. } \\
\text { Scoliosis, apex T.9-10. Awkward gait. } \\
\text { Cannot actively raise right pelvis }\end{array}$ & 2 & 6 & $\begin{array}{l}\text { Transplant weak. Pelvis level. Leg } \\
\text { length equal. Scoliosis worse. Gait } \\
\text { improved. Can actively raise right } \\
\text { pelvis }\end{array}$ \\
\hline 7 & Right & $\begin{array}{l}\text { Weak right lateral abdominals. Right } \\
\text { pelvic tilt. Right leg longer by } 2 \text { centi- } \\
\text { metres. Scoliosis, apex T.12, pliable. } \\
\text { Unable to raise right foot off ground } \\
\text { when walking }\end{array}$ & 2 & 5 & $\begin{array}{l}\text { Transplant active. Pelvis level. Leg } \\
\text { length equal. Scoliosis unchanged. } \\
\text { Can raise right foot off ground }\end{array}$ \\
\hline 8 & 'Right & $\begin{array}{l}\text { Weak right lateral abdominals. Right } \\
\text { pelvic tilt. Right leg longer by } 2 \text { centi- } \\
\text { metres. Scoliosis, apex L. } 3 \text {, fixed. } \\
\text { Walks with circumduction on the right }\end{array}$ & 2 & 0 & $\begin{array}{l}\text { Transplant active. Pelvic tilt slightly } \\
\text { less. Disparity in leg length reduced } \\
\text { to } 1 \frac{1}{2} \text { centimetres. Scoliosis un- } \\
\text { changed. Gait improved }\end{array}$ \\
\hline 9 & Left & $\begin{array}{l}\text { Weak left lateral abdominals. Left } \\
\text { pelvic tilt. Scoliosis, apex T.12 }\end{array}$ & 1 & 11 & $\begin{array}{l}\text { Transplant passive. Pelvis level. } \\
\text { Scoliosis unchanged }\end{array}$ \\
\hline 10 & Right & $\begin{array}{l}\text { Weak right lateral abdominals. Right } \\
\text { leg longer by } 2 \text { centimetres. Right } \\
\text { pelvic tilting. Few steps (braces and } \\
\text { crutches). Scoliosis, apex L.4, partly } \\
\text { fixed }\end{array}$ & $x^{2}$ & 11 & $\begin{array}{l}\text { Transplant weak. Pelvis level. Leg } \\
\text { length equal. Walks much farther and } \\
\text { better. Scoliosis unchanged }\end{array}$ \\
\hline 11 & Right & $\begin{array}{l}\text { Weak right lateral abdominals. Right } \\
\text { pelvic tilt. Right leg longer by } 2 \text { centi- } \\
\text { metres. Can hardly walk (braces and } \\
\text { crutches); cannot lift the right leg off } \\
\text { the ground }\end{array}$ & 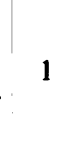 & 11 & $\begin{array}{l}\text { Transplant passive. Pelvic level. Leg } \\
\text { length equal. Walks better and for } \\
\text { longer distances }\end{array}$ \\
\hline 12 & Left & $\begin{array}{l}\text { Weak left lateral abdominals. Scol- } \\
\text { iosis, apex L.4, pliable }\end{array}$ & 1 & 8 & $\begin{array}{l}\text { Transplant active. Scoliosis un- } \\
\text { changed }\end{array}$ \\
\hline 13 & Right & $\begin{array}{l}\text { Weak right lateral abdominals. Right } \\
\text { pelvic tilt. Scoliosis, apex L.2-3, } \\
\text { pliable }\end{array}$ & 1 & 8 & $\begin{array}{l}\text { Transplant active. Pelvis level. } \\
\text { Scoliosis slightly improved. Walks } \\
\text { (braces and crutch) }\end{array}$ \\
\hline 14 & Right & $\begin{array}{l}\text { Left leg longer by } 2 \text { centimetres. } \\
\text { Scoliosis, apex T. } 11 \text {, pliable. Thoraco- } \\
\text { pelvic instability. Walks (braces and } \\
\text { crutches) }\end{array}$ & 1 & 8 & $\begin{array}{l}\text { Transplant active. Disparity of leg } \\
\text { length reduced } \frac{1}{2} \text { centimetre. Scoliosis } \\
\text { unchanged }\end{array}$ \\
\hline
\end{tabular}


TABLE II-continued

\begin{tabular}{|c|c|c|c|c|c|}
\hline $\begin{array}{l}\text { Case } \\
\text { number }\end{array}$ & $\begin{array}{c}\text { Side } \\
\text { affected }\end{array}$ & Indications & $\begin{array}{c}\text { Fo } \\
\text { year }\end{array}$ & $\begin{array}{l}\text { N-up } \\
\text { oonths }\end{array}$ & Result \\
\hline 15 & Left & $\begin{array}{l}\text { Weak left lateral abdominals. Left } \\
\text { pelvic tilt. Left leg longer by } 3 \text { centi- } \\
\text { metres. Scoliosis, apex L.3, pliable }\end{array}$ & 1 & 6 & $\begin{array}{l}\text { Transplant passive. Pelvis level. Leg } \\
\text { length equal. Scoliosis slightly im- } \\
\text { proved. Walks (braces and crutch) }\end{array}$ \\
\hline 16 & Left & $\begin{array}{l}\text { Weak left lateral abdominals. Left } \\
\text { pelvic tilt }\end{array}$ & 1 & 4 & Transplant active. Gait improved. \\
\hline 17 & Right & $\begin{array}{l}\text { Right leg longer. Scoliosis, apex T.12, } \\
\text { partly fixed }\end{array}$ & 1 & 4 & $\begin{array}{l}\text { Leg length equal. Transplant passive. } \\
\text { Scoliosis slightly worse. Walks }\end{array}$ \\
\hline 18 & Right & $\begin{array}{l}\text { Right pelvic tilt. Scoliosis, apex L.1, } \\
\text { pliable }\end{array}$ & 1 & 4 & $\begin{array}{l}\text { Transplant active. Pelvis level. Scoli- } \\
\text { osis unchanged. Walks (brace and } \\
\text { crutch) }\end{array}$ \\
\hline 19 & Left & $\begin{array}{l}\text { Weak left lateral abdominals. Left } \\
\text { pelvic tilt. Left leg longer. Scoliosis, } \\
\text { apex L.2, partly fixed }\end{array}$ & 1 & 2 & $\begin{array}{l}\text { Transplant passive. Pelvis level. Right } \\
\text { leg longer from contracture of ilio- } \\
\text { tibial band. Scoliosis worse. Walks } \\
\text { between parallel bars (braces). }\end{array}$ \\
\hline 20 & Right & $\begin{array}{l}\text { Weak right lateral abdominals. Right } \\
\text { pelvic tilt. Scoliosis, apex L.1-2, partly } \\
\text { fixed. Defective gait }\end{array}$ & 1 & 2 & $\begin{array}{l}\text { Transplant active. Scoliosis slightly } \\
\text { improved. Pelvic tilt improved. Gait } \\
\text { improved }\end{array}$ \\
\hline 21 & Right & $\begin{array}{l}\text { Right leg longer by } 1 \text { centimetre. Scol- } \\
\text { iosis, apex L.4-5, partly fixed. Walks } \\
\text { very badly }\end{array}$ & 1 & 1 & $\begin{array}{l}\text { Scoliosis unchanged. } \\
\text { active. Gait improved }\end{array}$ \\
\hline 22 & Right & $\begin{array}{l}\text { Weak right lateral abdominals. Right } \\
\text { pelvic tilt. Scoliosis, apex L.2-3, partly } \\
\text { fixed }\end{array}$ & 1 & 1 & $\begin{array}{l}\text { Transplant passive. Pelvic tilt im- } \\
\text { proved. Scoliosis slightly improved }\end{array}$ \\
\hline 23 & Left & $\begin{array}{l}\text { Weak left lateral abdominals. Left } \\
\text { pelvic tilt. Scoliosis, apex L.2-3. Dips } \\
\text { to left when walking }\end{array}$ & 1 & 3 & $\begin{array}{l}\text { Transplant active. Scoliosis corrected } \\
\text { (improved). Still dips when walking. } \\
\text { Sits up with more ease }\end{array}$ \\
\hline 24 & Left & $\begin{array}{l}\text { Weak left lateral abdominals. Left } \\
\text { pelvic tilt. Scoliosis, apex L.1-2. Can } \\
\text { just walk (braces and crutches) }\end{array}$ & 1 & 1 & $\begin{array}{l}\text { Transplant active. Scoliosis un- } \\
\text { changed. Walking no better. }\end{array}$ \\
\hline
\end{tabular}

forward. The only disturbing feature seven months after operation was pain localised to the costal attachment of the transplant. Radiographs revealed that the insertion of the transplant was slowly working its way through the rib and there was a considerable amount of heterotopic bone at the site of trauma. When examined again two years after operation this patient was free from pain.

Scoliosis was measured on radiographs of the spine taken routinely at three-monthly intervals in each child showing any tendency to a spinal deformity, with the patient lying supine.

In assessing post-operative correction of scoliosis a curve that differed from the preoperative one by only a few degrees was defined as "unchanged" since a small difference is within the margin of error in repeating the position of the child-those with differences of about 10 degrees are described as "slightly worse" or "slightly improved." Those with differences exceeding 10 degrees are defined as "improved" or "worse." Actual grading of scoliosis in degrees has been omitted from the tables. Scoliosis was estimated also from comparison of clinical photographs.

In nineteen patients there was scoliosis before operation and five of them improved, nine remained unchanged, and in five the curve continued to deteriorate after operation. In the five patients who improved three of the transplants were active and two passive; all had a correctable scoliosis before operation with the apex at L.3. One of these children has been wearing a Milwaukee brace for two years. Of the nine unchanged eight had active and

vOL. 38 B, NO. 2, MAY 1956 


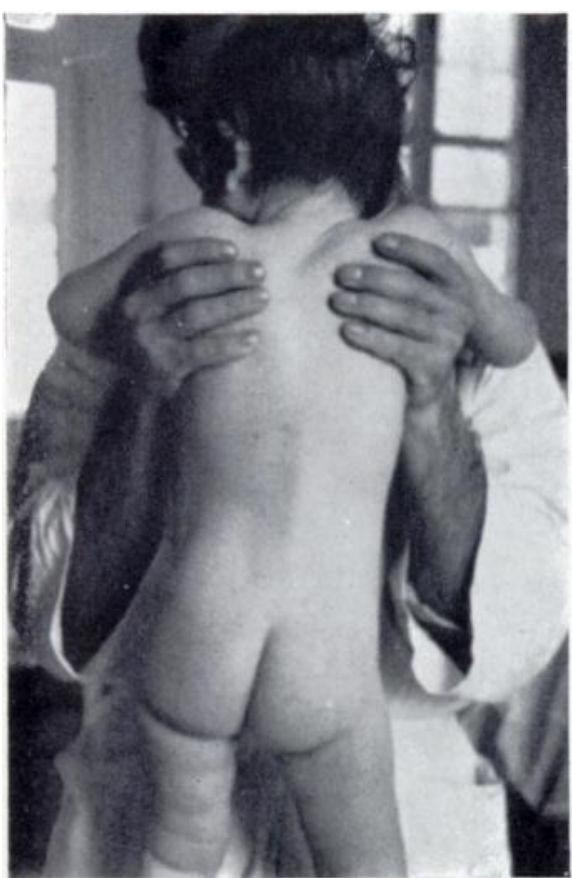

FIG. 6

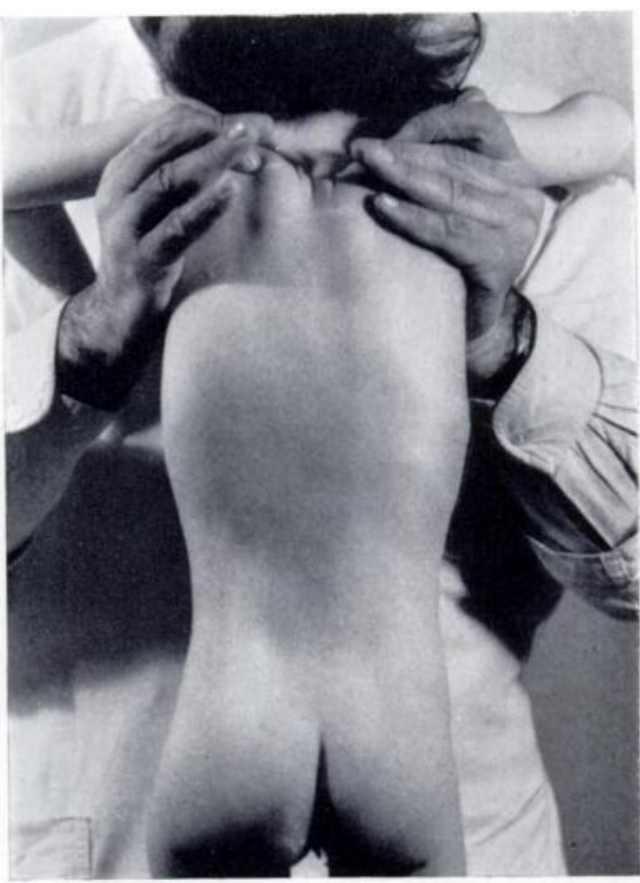

FIG. 7

Figure 6-Before operation. Right pelvic drop when the child is suspended and relaxed. Figure 7After operation. Right pelvic drop is corrected. The child can lift the right side of the pelvis by lifting the ipsilateral thorax because it is a passive transplant.

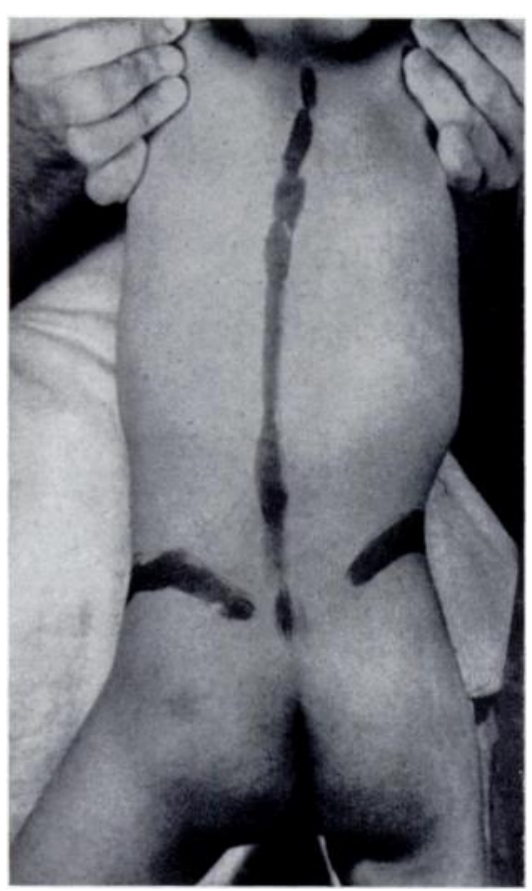

Fig. 8

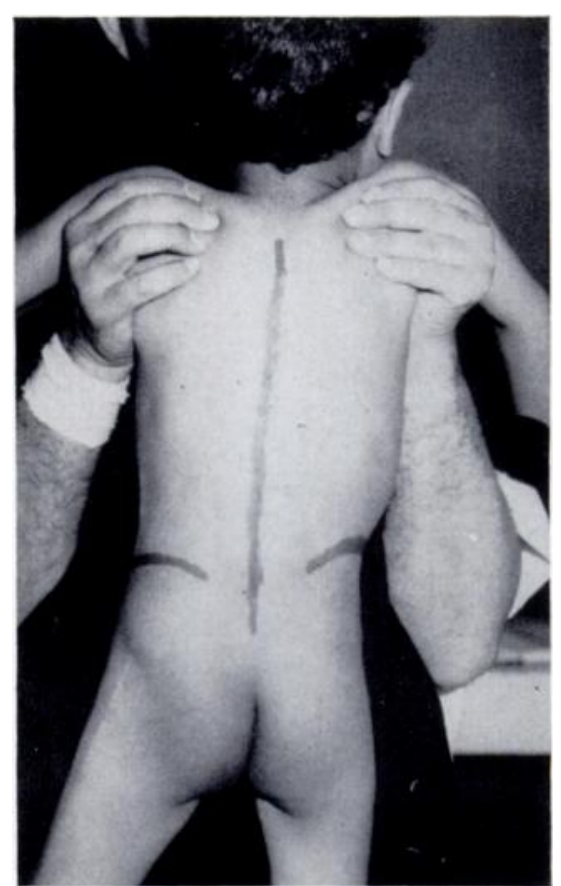

Fig. 9

Figure 8-Before operation in suspension. Pelvic drop to the left and scoliosis. Figure 9After operation in suspension. Scoliosis almost corrected with active abduction of the thigh which causes a lift of the pelvis on that side through the active transplant which can be seen bulging under the skin. 
one a passive transplant and the apex of scoliosis in these lay between T.12 and L.4; four of them had a partly fixed spinal curve before operation, and five a pliable one, and one has been wearing a Milwaukee brace for one year.

Figure 6 shows that when the child was suspended before operation there was an evident scoliosis; it was caused by weak right lateral abdominal muscles. Figure 7 shows that after operation the right pelvic drop was corrected. This child lifts the right side of the pelvis by raising the thorax to which the passive transplant is attached.

Figure 8 shows a child before operation in hanging position and the pelvic tilt and scoliosis can be clearly seen. Figure 9 shows the same child after operation, again in the same suspended position and performing an active abduction of the thigh which causes contraction of the tensor fasciae latae and tension of the ilio-tibial band (both can be seen bulging under the skin) resulting in active lifting of the pelvis on that side and correction of scoliosis.

Of the five children whose scoliosis deteriorated after the operation two became seriously worse. One of them had a weak transplant fixed to the ninth rib, which, most unfortunately, corresponded with the apex of the scoliosis (T.9-10, Case 6) and the other one had a passive transplant for a partly fixed scoliosis (Case 19). The remaining three patients, who deteriorated only slightly, had before operation either a partly fixed scoliosis or a passive transplant, or both.

Analysis of these nineteen children suffering from scoliosis reveals that satisfactory results were obtained if scoliosis was correctable before operation, if its apex lay not above T.12* and the transplant was active.

The results obtained in this limited series suggest that the operation can, at least temporarily, improve, check or slow down the relentless progress of paralytic scoliosis in children who contracted poliomyelitis during the first year of life. Proper application of this operation may therefore allow such children to reach the age in which fusion of the spine can be performed with much better chance of a sound union and without suffering from such a crippling scoliosis as otherwise they might.

\section{CONCLUSION}

The important gains from operation are the improvement in thoraco-pelvic stability, by establishment of a dynamic bridge between the two elements, and the improvement in the balance of asymmetrically paralysed abdominal muscles.

1. Lateral pelvic tilt-This applies only when the tilt is caused by weakness of the lateral abdominal muscles of one side which may be associated with weakness of the ipsilateral quadratus lumborum. Such tilts are often combined with abduction contractures of the related hip which will require correction during the operation. An active ilio-tibial band transplant will improve the power of the weak lateral abdominal muscles and quadratus lumborum, help to maintain the correction of the tilt and adjust the disparity in leg length caused by the tilt.

2. Defective gait-Lurching gait is mostly caused by weakness of the gluteus medius of one or other side, but the lateral abdominal muscles are also concerned. When the gluteal muscles are intact there is still an alteration in the gait if the lateral abdominal muscles are weak. Under such circumstances in order to swing the foot forward on the affected side, the pelvis, although supported by the opposite gluteus medius, still requires assistance from the lateral abdominal muscles of the affected side. These weak abdominal muscles are supplemented by throwing forward the same half of the body and at each step there is a " screw like" motion of the trunk. In so far as the operation adds to the power of the lateral abdominal muscles the gait can be assisted. In the absence of all power in the lateral abdominal muscles and the gluteals the operation has a place in facilitating the use of crutches and braces.

* In a recent child not included in this series the free end of the ilio-tibial band was inserted into the sixth rib because the apex of scoliosis lay at T.8-9. The early result is good.

VOL. 38 B, NO. 2, MAY 1956 
3. Scoliosis-The operation can help in so far as it maintains correction of pelvic tilt. Weakness of lateral abdominal muscles is usually one of the factors in development of the lumbar or lumbo-dorsal scoliosis. By strengthening of these muscles the deformity may be halted, its progress retarded or possibly correction may be achieved.

It is plain that this muscle-tendon transplant cannot be regarded as an adequate replacement for completely paralysed lateral abdominal muscles. It is however an adjuvant to the means employed to diminish the disability of the patient who is so seriously incapacitated that bulky apparatus is required for achievement of any sort of walking. When the gluteal muscles are intact the transplant is able to give material assistance to severely paralysed lateral abdominal muscles and to restore the relatively minor defect in the gait. Muscle imbalance in poliomyelitis is so potent a cause of primary deformity and of a chain of secondary deformities and disabilities, that the only logical treatment must be an attempt to reduce the lack of balance by the redistribution of the available muscle power to the greatest functional advantage. Any success in the increase of thoraco-pelvic stability in a virtually flail trunk is bound to be a material gain. The operation, in suitable circumstances, is therefore indicated at any age and ought not to be deferred after reasonable hope of muscle recovery has ended.

\section{SUMMARY}

1. A dynamic muscle-tendon transposition is described for supplementing the power of weak lateral abdominal muscles, and the details of the operative technique are given.

2. A clinical assessment of the results in a series of twenty-four patients is given.

3. The indications for the operation in poliomyelitis are suggested.

We are deeply grateful to Dr Leo Mayer for his constructive and continuous help ever since his second visit to Israel in 1953 when he had the first opportunity to see the early results of these operations. His work on the role of abdominal muscle deficiencies in paralytic scoliosis and his ilio-costal fascial graft gave us the basis for the development of this operation.

We wish to express our thanks to Sir Harry Platt for reviewing a number of the patients during his visit to Israel, to Miss M. B. Kidd for taking charge of the post-operative rehabilitation, and to members of the staff of the Orthopaedic Department of Zrifin Hospital who gave us their unstinted help.

\section{REFERENCES}

Forrester-Brown, M. (1950): Paralysis. In Modern Trends in Orthopaedics. Edited by Sir Harry Platt. P. 269. London: Butterworth \& Co. (Publishers) Ltd.

Lowman, C. L. (1932): The Relation of the Abdominal Muscles to Paralytic Scoliosis. Journal of Bone and Joint Surgery, 14, 763.

MAYeR, L. (1931): Fixed Paralytic Obliquity of the Pelvis. Journal of Bone and Joint Surgery, 13, 1.

MAYer, L. (1936): Further Studies of Fixed Paralytic Pelvic Obliquity. Journal of Bone and Joint Surgery, $18,87$.

MAYer, L. (1944): The Significance of the Iliocostal Fascial Graft in the Treatment of Paralytic Deformities of the Trunk. Journal of Bone and Joint Surgery, 26, 257. 